\title{
Intimacy and Couple Satisfaction: The Moderating Role of Romantic Attachment
}

\author{
Cathy Dandurand ${ }^{1} \&$ Marie-France Lafontaine ${ }^{1}$ \\ ${ }^{1}$ School of Psychology, University of Ottawa, Ottawa, Canada \\ Correspondence: Cathy Dandurand, School of Psychology, University of Ottawa, 136 Jean-Jacques, Ottawa, \\ Ontario, K1N 6N5, Canada. Tel: 1-613-421-6905. E-mail: cdand051@uottawa.ca
}

Received: November 5, 2012

Accepted: December 11, 2012 Online Published: February 21, 2013

doi:10.5539/ijps.v5n1p74

URL: http://dx.doi.org/10.5539/ijps.v5n1p74

\begin{abstract}
The present study extends findings regarding the established relation between intimacy (emotional and sexual) and couple satisfaction by investigating dyadic processes of intimacy (actor and partner effects) and the moderating role of gender and insecure romantic attachment on this relation. Using a sample of 117 heterosexual couples, results analyzed through an Actor-Partner-Interdependence Model revealed that only actor and partner emotional intimacy were significantly and positively related with actor couple satisfaction when examined simultaneously with sexual intimacy; stronger effects were revealed for actor versus partner emotional intimacy. Actor avoidant attachment was also found to moderate the aforementioned association, such that a decreased positive relation was demonstrated between actor emotional intimacy and actor couple satisfaction. Thus, results suggest that emotional intimacy may play a less important role in the attainment of satisfactory couple relationships amongst individuals exhibiting higher attachment avoidance. The myriad of additional practical and clinical implications of findings are discussed.
\end{abstract}

Keywords: intimacy, attachment, relationship satisfaction, couple relationship

\section{Introduction}

Romantic intimacy is regarded as one of the highest values of human existence and is considered as imperative for healthy functioning (Bowlby, 1969/1982). Research has corroborated this outlook by revealing that high levels of romantic intimacy in one's relationship are one of the strongest predictors of physical health (e.g., lower rates of illness, increased recovery from illness; Hook, Gerstein, Detterich, \& Gridely, 2003), psychological well-being (e.g., reduced risk for depression, therapy seeking, life satisfaction; Hobfoll \& Leiberman, 1989; Hook et al., 2003; Horowitz, 1979; Morris, Morris, \& Britton, 1988), and couple satisfaction (Schaefer \& Olson, 1981). Taken as a whole, the attainment of intimacy can be viewed as an imperative means by which to create meaningful and satisfactory bonds between individuals, in turn leading to an array of positive outcomes.

Accordingly, intimacy has come to be regarded by many prominent psychological figures as a universal human need (Erikson, 1950; Rogers, 1972; Sullivan, 1953). Yet research has shown that the level of intimacy desired in one's romantic relationship may vary depending on an individual's attachment patterns (Feeney \& Noller, 1991), with individuals exhibiting insecure forms of attachment being less able to effectively pursue intimacy goals (Hazan \& Shaver, 1987). Provided the established link between romantic intimacy and couple satisfaction (Schaefer \& Olson, 1981), and the abundance of research revealing attachment-based differences in romantic intimacy motives (Feeney \& Noller, 1991), the current study sought to investigate a novel model examining romantic attachment as a moderator of the former relation.

The investigation of moderator effects (a variable which influences the strength or direction of the relation between a predictor and outcome) has been shown to be an exemplary and integral manner by which to elucidate the relation between variables and is regarded as an indication of the advanced nature of a field of investigation (Aguinis, Boik, \& Pierce, 2001; Cohen, Cohen, West, \& Aiken, 2003). Accordingly, the overarching aim of the current study was to gain an increased understanding of the important link between intimacy and couple satisfaction by highlighting for whom this relation may differ. Additionally, given contemporary agreement of intimacy as a multifaceted relational phenomenon (Miller \& Lefcourt, 1982; Oden 1974; Schaefer \& Olson, 1981; Tolstedt \& Stokes, 1983) that is mutually determined by both partners (Schaefer \& Olson, 1981), we sought to further broaden this analysis by a comprehensive and dyadic examination of both partners' levels of two 
well-established facets of intimacy: emotional intimacy (defined as the experience of closeness of feeling and the ability and freedom to share openly in a non-defensive atmosphere where there is supportiveness and genuine understanding) and sexual intimacy (defined as the experience of general affection, touching, physical closeness, and sexual activity; Schaefer \& Olson, 1981). The interrelations demonstrated between intimacy, romantic attachment, and couple satisfaction follow in support of the study's proposed moderator models.

\subsection{Intimacy, Attachment, and Couple Satisfaction: Theoretical Links}

Attachment frameworks are considered to be one of the most comprehensive theories for understanding relationship behaviours, preferences, and motives, including intimacy desires (Mikulincer \& Shaver, 2007). In this way, attachment theory has been essential in elucidating how individuals exhibiting insecure forms of attachment commonly have the greatest difficulty navigating intimacy needs and desires in their relationships. Briefly, insecure attachments are believed to ensue in early life when one is exposed to emotionally unavailable attachment figures. As a means to cope with reduced caregiver responsiveness, one of two defensive strategies may develop, known as the hyperactivation or deactivation of attachment needs (Cassidy \& Berlin, 1994; Cassidy \& Kobak, 1988; Mikulincer \& Shaver, 2007). The primary aim of hyperactivation is to promote increased support and protection from an attachment figure that is sporadically available. Conversely, the primary goal of deactivation is to maintain emotional distance and strive for self-reliance; an approach that develops as a means to adjust to unavailable and unresponsive attachment figures. Although once adaptive to their particular caregiver circumstances, insecure attachment patterns commonly go on to bias preferences, perceptions, and behaviours in subsequent adult relationships (Collins \& Read, 1990) in a way which negatively interferes with the attainment of couple satisfaction (Mikulincer \& Shaver, 2007).

In adulthood, romantic partners typically serve as individuals' primary attachment figure (Hazan \& Shaver, 1987). Insecure attachments in couple relationships are broadly manifested in terms of anxiety over abandonment (defined as fears of abandonment and anger about separation in romantic relationships) and avoidance of intimacy (defined as a desire for limited closeness and the suppression of emotions in romantic relationships; Brennan, Clark, \& Shaver, 1998). Overall, anxiously attached individuals' prototypical use of hyperactivation strategies is typically exhibited in their romantic relationship as worries about rejection, concerns about the availability of others, dependency, and incessant attempts to provide and obtain greater emotional intimacy to and from their partner in a way that can be experienced as overbearing and arduous (Collins \& Read, 1990; Feeney \& Noller, 1991; Ognibene \& Collins, 1998). Anxiously attached individuals are similarly shown to indiscriminately use sex as a means by which to attain acceptance, love, and avoid abandonment (Birnbaum, Reis, Mikulincer, Gillath, \& Orpaz, 2006; Feeney \& Collins, 2003), and thus, report enjoying the more intimate aspects of sex (kissing, cuddling, touching) than the act of sexual intercourse itself (Hazan, Zeifman, \& Middleton, 1994). Taken as a whole, anxiously attached individuals' exaggerated threat perception, fears of abandonment, and unfulfilled need to have greater mutual love may require them to experience higher levels of emotional and sexual intimacy by both oneself and their partner in order to feel satisfied in their romantic relationship. Thus, attachment anxiety may moderate the established relation between intimacy (emotional and sexual) and couple satisfaction, such that individuals exhibiting higher attachment anxiety may demonstrate a stronger positive relation between one's own or one's partner's intimacy and one's couple satisfaction when contrasted with individuals reporting lower attachment anxiety.

In contrast, avoidantly attached individuals' prototypical use of deactivation strategies is customarily displayed in their romantic relationship as the minimization of attachment needs and emotions (Bartholomew \& Horowitz, 1991; Fraley \& Shaver, 2000), a lessened desire for closeness and emotional intimacy (Collins \& Feeney, 2003), and an overemphasis on autonomy needs (Feeney, 1999; Feeney \& Noller, 1991). Such individuals are correspondingly more likely to display negative affect upon their partner's attempts to seek greater emotional intimacy and to regard these efforts as needy and dependent (Collins \& Feeney, 2003). As such, both one's own and one's partner's intimacy can be experienced as jeopardizing efforts to sustain reduced levels of intimacy. Avoidantly attached individuals are also shown to be less inclined to use touch (e.g., kissing, cuddling, hugging) to express affection or seek care from their partner (Brennan, Wu, \& Loev, 1998; Hazan et al., 1994) and demonstrate a greater likelihood of separating love and sex (Brennan \& Shaver, 1995). Thus, their deactivation of emotions, discomfort with intimacy, and emphasis on self-reliance may require them to experience lower levels of emotional and sexual intimacy by both oneself and one's partner in order to feel satisfied in their romantic relationship. In this way, avoidant attachment may moderate the relation between intimacy (emotional and sexual) and couple satisfaction, such that individuals exhibiting higher attachment avoidance may demonstrate a lessened positive relation between one's own or one's partner's intimacy and one's couple satisfaction when contrasted with individuals reporting lower attachment avoidance. 
Altogether, the examination of such stipulations would reveal whether an attachment perspective elucidates for whom there may be a differential relation (i.e., strengthened or weakened link) between intimacy and couple satisfaction. Provided the imperative function of intimacy in romantic relationships, and the profound impact that such relationships can have on one's general well-being (Mikulincer \& Shaver, 2007), understanding discrepancies in intimacy-based experiences and their potentially differential relation with one's couple satisfaction could reveal important theoretical, empirical, and clinical implications regarding the establishment of satisfactory couple relationships. Empirical links established between our variables of interest provide support for the aforementioned inferences.

\subsection{Intimacy, Attachment, and Couple Satisfaction: Empirical Links}

Empirical research has consistently demonstrated a positive link between emotional intimacy and couple satisfaction. Both Schaefer and Olson (1981), in addition to Greeff and Malherbe's (2001) findings, have shown that higher levels of one's emotional intimacy were related with higher levels of one's marital satisfaction. This was corroborated by Sanderson and Cantor's (2001) results which revealed that both one's and one's partner's [emotional] intimacy goals were linked with one's relationship satisfaction, with higher correlation coefficients demonstrated for one's intimacy goals. Despite research examining both partners' intimacy goals (i.e., desire/motives for intimacy), a dyadic examination of both partners' experience of intimacy (i.e., current levels of intimacy) has yet to be implemented in relation to one's relationship quality. Given that one's intimacy goals may differ from one's experience of intimacy, the novel examination of both partners' current experience of emotional intimacy is required for a more thorough understanding of the link between intimacy and couple satisfaction.

Physical forms of intimacy are also shown to provide important avenues by which individuals can express themselves and obtain care and validation from their partner (Reis \& Patrick, 1996). This is consistent with both Schaefer and Olson's (1981), as well as Greeff and Malherbe's (2001) research, which revealed that higher levels of one's sexual intimacy were related with higher levels of one's marital satisfaction. Such findings are similarly in line with those of Tolstedt and Stokes (1983) demonstrating a positive relation between one's physical intimacy and one's marital satisfaction, with physical intimacy explaining variance in marital satisfaction over and above that shown for other forms of intimacy (e.g., affective or verbal intimacy), despite this effect being small. Studies have yet to examine both partners' level of sexual intimacy (goals or current experiences) in relation to one's couple satisfaction. Provided the acknowledged multifaceted and dyadic nature of intimacy (Schaefer \& Olson, 1981), it remains important to clearly delineate the relative contribution of both one's and one's partner's current level of emotional and sexual intimacy for a comprehensive understanding of the attainment of couple satisfaction. The higher correlation/regression coefficients revealed for emotional versus sexual intimacy (Greeff \& Malherbe, 2001; Schaefer \& Olson, 1981; Tolstedst \& Stokes, 1983), as well as for actor versus partner emotional intimacy (Sanderson \& Cantor, 2001), strongly suggest that emotional intimacy will exhibit a more central role in relationship quality, with actor effects demonstrating the strongest relation.

Lastly, numerous empirical studies have demonstrated a link between insecure attachment and intimacy (Guerrero, 1996; Mikulincer \& Shaver, 2007; Pielage, Luteijn, \& Arrindell, 2005; Pistole, 1994), as well as insecure attachment and couple satisfaction (Mikulincer \& Shaver, 2007), with the majority of studies demonstrating a negative association between these constructs. Given the current study's focus on expanding knowledge of intimacy and its link with couple satisfaction, and that a relation between the above variables (i.e., between a moderator and a predictor or outcome) is not a required stipulation for establishing moderation, for brevity, interested readers are invited to refer to the aforesaid authors for a detailed empirical overview of these associations.

\subsection{Current Study Objectives}

Despite previous valuable contributions to the related literature, we aimed to further expand on prior research examining intimacy in the context of couple relationships in several ways. First, although research demonstrates that sexual intimacy is an important feature of relationship quality (Greeff \& Malherbe, 2001; Schaefer \& Olson, 1981; Tolstedst \& Stokes, 1983), the preponderance of studies has concentrated solely on emotional intimacy. Even when sexual facets are examined, the focus has been primarily placed on sexual desires, sexual motivations, and sexual satisfaction while overlooking needs for closeness (Marelich, 2008). Provided the important function of both emotional and sexual facets of intimacy, this study sought to gain a greater understanding of their relative importance in order to further elucidate the elements of intimacy required for satisfactory couple relationships.

Second, intimacy is shown to be a dyadic process that must be regulated in a way which accommodates both partners (Lipert \& Prager, 2001; Prager \& Roberts, 2004; Reis \& Shaver, 1988; Schaefer \& Olson, 1981; Sexton \& Sexton, 1982). Yet, studies have primarily focused on an individual's experience of intimacy and its relation with 
their own relationship quality. Accordingly, the current study endeavoured to investigate an Actor-Partner Interdependence Model (APIM) in order to conduct a novel exploration of the systemic links between both partners' emotional and sexual intimacy and one's couple satisfaction. Explicitly, APIM permits the examination of an individual's predictor variable(s) on their outcome(s) (termed actor effects), as well as their partner's outcome(s) (termed partner effects). This approach is aligned with the most recent advances in couple research advocating for the investigation of dyads as a system in contrast to partners as separate entities.

Third, attachment research demonstrates how individuals enter into relationships carrying with them a history of personal and interpersonal experiences that shape their motives and preferences, including intimacy desires (Feeney \& Collins, 2003). However, studies have yet to explore whether attachment processes may impact (i.e., moderate) the relation between intimacy and couple satisfaction. Given that the potential influence of one's romantic attachment on one's couple satisfaction may differ for emotional versus sexual facets of intimacy, and correspondingly, for one's intimacy when contrasted with one's partner's intimacy, the examination and relative contrasting of both partners' level of emotional and sexual intimacy in relation to one's couple satisfaction was regarded as important for an inclusive and thorough understanding of the moderating role of romantic attachment.

For instance, given avoidant individuals' ability to separate love and sex (Brennan \& Shaver, 1995), it is plausible that moderation effects of attachment avoidance may be weaker for sexual versus emotional facets of intimacy if the former is perceived as less intrusive to their preferred desires for more limited interpersonal closeness. Likewise, it is conceivable that anxiously attached individuals' fears of abandonment (Brennan et al., 1998), and corresponding desire to attain higher levels of mutual intimacy (Pistole, 1994), may lead them to be equally sensitive to both their own and their partner's level of intimacy when contrasted with individuals higher in attachment avoidance. Thus, in short, the overall objective of the current study was to implement an original and systematic model investigating actor romantic attachment as a moderator of the relation between actor versus partner emotional and sexual intimacy and actor couple satisfaction. Lastly, due to inconsistent gender effects of intimacy demonstrated within the literature, with some studies revealing gender differences for emotional and/or sexual intimacy (Reiss, 1998; Greeff \& Malherbe, 2001; Tamaldage \& Dabbs, 1990) and others reporting no such gender effect (McCabe, 1999), potential gender differences were investigated for all study relations to ascertain whether intimacy and its relation with couple satisfaction (including the potential moderating role of attachment) may differ for men and women.

\subsection{Hypotheses}

First, it was hypothesized that a positive linear relation would be demonstrated between actor and partner intimacy (emotional and sexual) and actor couple satisfaction. Second, it was hypothesized that the positive relation between actor and partner intimacy (emotional and sexual) and actor couple satisfaction would be stronger amongst those exhibiting higher actor anxiety over abandonment. Third, it was hypothesized that the positive relation between actor and partner intimacy (emotional and sexual) and actor couple satisfaction would be weaker amongst those exhibiting higher actor avoidance of intimacy. Fourth, it was hypothesized that emotional intimacy, when contrasted with sexual intimacy, would reveal a stronger relation with actor couple satisfaction. Fifth and lastly, it was hypothesized that actor intimacy, when contrasted with partner intimacy, would demonstrate a stronger relation with actor couple satisfaction. Due to inconsistent gender findings in the literature regarding intimacy, no a priori hypotheses were put forth for gender effects.

\section{Method}

\subsection{Participants}

The sample was comprised of 117 English-speaking heterosexual couples from the community of Ottawa, Ontario and its surrounding regions. Eligibility criteria for the study included: a) being 18 years of age or older, b) being currently involved with the same partner for at least 12 months, and c) living with their partner for at least 6 months. The mean age of participants was 33.61 years $(S D=13.46)$ and the average duration of the romantic relationship was 6.46 years $(S D=7.92)$, with $43.2 \%$ of the couples married for an average duration of 6.26 years $(S D=12.04)$. The preponderance of couples did not have children $(83.76 \%)$. The ethnicity of participants was 92.5\% Caucasian, 2.3\% Hispanic, 1.8\% Black, 1.4\% Asian, 0.5\% Middle Eastern, 0.5\% First Nation, and 1.0\% other. The majority of participants held a university degree (61.80\%), with an average annual income of $\$ 44100$ (Canadian dollars).

\subsection{Procedure}

The current study was embedded within a larger longitudinal research study that consisted of three time phases, each occurring approximately 12 months apart. The sample used for this study comprised of individuals who 
either a) participated in this component of the study for the first time (phase $1 ; n=56$ ), or b) participated as a follow-up to their participation 12 months prior (phase $2 ; n=61$ ). All participants were voluntarily recruited by means of newspapers, community advertisements, and local events. Eligible participants were invited to participate in a 2.5 hour testing session during which they completed questionnaires, among other tasks. To minimize attrition rates among participants in the follow-up phase only, those unable to attend laboratory sessions were provided the option to have questionnaires sent to their home via regular mail or a secure and encrypted internet site (Survey Monkey). Prior to participating, partners were informed of the nature and purpose of the study, the procedure, and confidentiality issues. All participants were requested to complete the questionnaires independently from their partner. The questionnaire package relevant to the current study took approximately 20 minutes to complete. A Multivariate Analysis of Variance (MANOVA) revealed no statistically significant differences between individuals participating for the first time (phase 1) or as a follow-up (phase 2) on measures of romantic attachment (fears of abandonment and avoidance of intimacy), intimacy (emotional and sexual), and couple satisfaction.

\subsection{Measures}

\subsubsection{Sociodemographic Questionnaire}

This questionnaire was administered to gather relevant personal (e.g., age, ethnicity, mother tongue, educational level, salary, etc.) and relationship demographics (e.g., relationship/marital status, relationship length, etc.).

\subsubsection{Personal Assessment of Intimacy in Relationships (PAIR; Schaefer \& Olson, 1981)}

The PAIR inventory is a 36-item instrument that assesses five types of intimacy: emotional, social, sexual, recreational, and intellectual. Additionally, this measure contains a "conventionality" scale which measures the extent to which someone is "faking good". For the purposes of this study, only facets of emotional intimacy (e.g., "My partner listens to me when I need someone to talk to"), sexual intimacy (e.g., "Sexual expression is an essential part of our relationship") and conventionality were included (e.g., "Every new thing I have learned about my partner has pleased me"). All subscales of the PAIR consist of 6-items asking participants to indicate their responses on a scale ranging from $0=$ Strongly Disagree to $4=$ Strongly Agree, with a midpoint of $2=$ Neutral. Scores are summed for each subscale, with higher scores indicative of higher intimacy or "faking good" (score range $=0-24)$. The alpha coefficients for the current study were .83 for emotional intimacy, .76 for sexual intimacy, and .82 for conventionality, as compared with .75 and .77 that were originally established by Schaefer and Olson (1981) for emotional and sexual intimacy. Although a reliability coefficient for conventionality was not reported within their original study, item factor loadings for their scale were demonstrated to appropriately range between .55 to .66 (Schaefer \& Olson, 1981).

\subsubsection{Experiences in Close Relationships (ECR; Brennan et al., 1998)}

This 36-item scale is a widely used measure of adult romantic attachment and is comprised of two subscales: anxiety over abandonment (e.g., "I worry about being rejected and abandoned") and avoidance of intimacy (e.g., "Just when my partner starts to get close to me I find myself pulling away"). Responses are indicated on a 7-point Likert scale ranging from $1=$ Disagree Strongly to $7=$ Agree Strongly, with a midpoint of $4=$ Neutral/Mixed. Item scores are summed for each subscale, with higher scores indicative of higher anxiety or avoidance (score range $=18-126$ ). The ECR demonstrates excellent reliability coefficients and has been shown to be psychometrically superior when contrasted with three well-known attachment measures (Fraley, Waller, \& Brennan, 2000). The ECR has similarly been revealed to have good convergent validity and test-retest reliability scores (range $=.50$ and .75 ; Mikulincer $\&$ Shaver, 2007). In the present study, the internal reliability indices were .92 for anxiety over abandonment and .93 for avoidance of intimacy, as compared to .91 and .94 , respectively, that were originally reported by Brennan and colleagues (1998).

\subsubsection{Dyadic Adjustment Scale- 4 items (DAS-4; Sabourin, Valois, \& Lussier, 2005)}

The DAS-4 is a briefer version of the original 32-item DAS (Spanier, 1976), a widely used and psychometrically validated self-report measure of dyadic adjustment for individuals involved in a romantic relationship. The DAS-4 includes questions such as: "How often do you discuss or have you considered divorce, separation, or terminating your relationship?" Varying Likert-type scales are used and items are summed to obtain a global score, with higher scores reflecting higher levels of satisfaction with one's couple relationship (referred to within the article as couple satisfaction; score range $=0-21$ ). The scale has demonstrated good reliability (Cronbach's alpha $=.84)$, acceptable classification rates of distressed and non-distressed couples (.84 and .92 , respectively), and better predictive validity (i.e., couple dissolution over a 2-year period) than the DAS-32 (Sabourin et al., 2005). In the present study, the internal reliability of the scale was .80 . 


\section{Results}

\subsection{Preliminary Analyses}

All statistical analyses were conducted with SPSS (Statistical Package for the Social Sciences) version 20.0. Prior to conducting the main analyses, data were verified for problematic missing values, multivariate normality, and univariate and multivariate outliers. Single imputations (using the expectation-maximization algorithm) were used to replace missing data (less than $1 \%$ of the dataset, missing at random) due to its ability to maximize power and its advantage over other available methods (e.g., case deletion, mean substitution, and regression; Widaman, 2006). Normality assumptions and the presence of outliers were examined by means of histograms and boxplots, respectively. Normality assumptions were not met across the study variables (three negatively skewed, two positively skewed); skewed variables were logarithmically transformed. Following transformations, two univariate outliers were identified using boxplots and further transformed by bringing their values closer to the mean. A test of Mahalanobis distance revealed that the dataset did not contain any multivariate outliers. Homogeneity of variance and covariance assumptions were met across variables of interest as shown by the lack of a significant Levene's statistics and Box's M test, respectively. Linearity and multicollinearity were demonstrated by means of bivariate scatterplots and the variance inflation factor (VIF), respectively, across all variables.

\subsection{Descriptive Statistics}

Bivariate correlations were computed in order to verify preliminary relationships amongst variables and assess bidirectionality in couples (see Table 1). Small to moderate correlations were found between men's and women's emotional intimacy, sexual intimacy, and couple satisfaction, suggesting that the dyadic data were non-independent. The correlational analyses also revealed preliminary relationships amongst study variables, typically supporting our hypotheses. Generally, emotional and sexual intimacy, in both men and women, were shown to be positively related with their own and their partner's couple satisfaction. The only exception was the absence of a significant relation between men's sexual intimacy and women's couple satisfaction. Additionally, attachment insecurity in women and men (anxiety and avoidance) was generally shown to be significantly and negatively associated with both their own and their partner's emotional intimacy, sexual intimacy, and couple satisfaction. The only exceptions were the absence of significant relations between actor attachment anxiety and partner emotional/sexual intimacy (for both men and women), as well as between men's attachment anxiety and women's couple satisfaction.

Table 1. Means, standard deviations, and correlations between intimacy, romantic attachment, and couple satisfaction

\begin{tabular}{|c|c|c|c|c|c|c|c|c|c|c|}
\hline & 1 & 2 & 3 & 4 & 5 & 6 & 7 & 8 & 9 & 10 \\
\hline \multicolumn{11}{|l|}{ 1. ANX W } \\
\hline 2. ANX M & .118 & & & & & & & & & \\
\hline 3. AVD W & $.313 * *$ & .127 & & & & & & & & \\
\hline 4. AVD M & $.184^{*}$ & $.301 * *$ & $.185^{*}$ & & & & & & & \\
\hline 5. EI W & $-.445 * * *$ & -.079 & $-.600 * * *$ & $-.318^{* * *}$ & & & & & & \\
\hline 6. EI M & -.051 & $-.283^{* *}$ & $-.291 *$ & $-.531 * * *$ & $.464 * * *$ & & & & & \\
\hline 7. SI W & $-.226^{*}$ & -.068 & $-.430 * * *$ & $-.219^{*}$ & $.534 * * *$ & $.346^{* * *}$ & & & & \\
\hline 8. SI M & -.037 & $-.314 * *$ & $-.182 *$ & $-.446 * * *$ & .139 & $.507 * * *$ & $.390 * * *$ & & & \\
\hline 9. SAT W & $-.379 * * *$ & .103 & $-.528 * * *$ & $-.343 * * *$ & $.681 * * *$ & $.398 * * *$ & $.425^{* * *}$ & .146 & & \\
\hline 10. SAT M & $-.191^{*}$ & $-.232 *$ & $-.303 * *$ & $-.539 * * *$ & $.480 * * *$ & $.690 * * *$ & $.381 * * *$ & $.346^{* *}$ & $.491 * * *$ & \\
\hline Mean & 53.15 & 45.14 & 35.02 & 38.12 & 18.18 & 18.25 & 18.53 & 17.23 & 16.55 & 16.56 \\
\hline $\begin{array}{l}\text { Standard } \\
\text { Deviation }\end{array}$ & 1.49 & 1.47 & 1.54 & 1.46 & 1.43 & 1.39 & 1.27 & 1.43 & 1.26 & 1.30 \\
\hline
\end{tabular}

Bivariate correlations of primary study variables. Note. ${ }^{*} p<0.05, * * p<0.01, * * * p<0.001$. ANX $=$ attachment anxiety, $\mathrm{AVD}=$ attachment avoidance, $\mathrm{EI}=$ emotional intimacy, $\mathrm{SI}=$ sexual intimacy, $\mathrm{SAT}=$ couple satisfaction, $\mathrm{W}=$ women, $\mathrm{M}=$ men. 


\subsection{Primary Analyses}

One of the most fundamental issues in couple research is non-independence (Kenny, Kashy, \& Cook, 2006). Non-independence refers to when dyads (e.g., a romantic couple, parent/child, two friends) influence one another and therefore share a common variance. Given that relationship quality is found to be mutually determined by both partners (Hendrick, 1998), a plan of analysis utilizing the dyad was incorporated (APIM; Kenny \& Cook, 1999). Specifically, multilevel modelling, a technique highly recommended for the estimation of APIM parameters (Campbell \& Kashy, 2002; Kenny \& Cook, 2006), was employed. This technique includes the dyad as the highest unit of analysis, with individual partners nested hierarchically within the couple; for information on how data sets are structured within APIM and multilevel modelling readers are referred to Campbell and Kashy (2002), as well as Cook and Kenny (2005).

Multilevel modelling holds several advantages, including: (1) addressing the non-independence of dyadic data, (2) integrating both actor and partner effects into the same model, and (3) permitting the investigation of both main and indirect effects required for the examination of moderation models (Campbell \& Kashy, 2002). To test our hypotheses, multilevel modelling was examined using Linear Mixed Models (LMM; with the restricted maximum likelihood; REML). All significant moderation effects (as demonstrated by a significant interaction effect between a predictor and moderator) were plotted, as well as subsequently examined by means of simple slope tests, using the range of both predictor variables (intimacy and attachment) from one standard deviation below and above the mean as outlined by Aiken and West (1991). All significant effect size estimates $\left(\eta^{2}\right.$ : eta-square) were determined by comparing the residual variance of study models with and without significant predictor(s) or interaction(s) of interest, as outlined by Tabachnick and Fidell (2007).

To gain unbiased estimates of the hypothesized relations, all mixed-dyad independent variables were grand-mean centered (Kenny \& Cook, 2006). Given the use of distinguishable couples, gender was effect coded as male $=-1$ and female $=1$. A significance level of .05 was used throughout. While a power analysis has not been explicitly designed for APIM, the basis for this technique is regression. Using regression coefficients as the unit of analysis, it was determined that our sample size $(N=117$ dyads) afforded a power level of more than .95 to detect a medium effect $(r=.3)$ at an alpha level of .05 with models including 18 predictor variables (all interactions included; G*Power; Faul, Erdfelder, Lang, \& Buchner, 2007). Analyses proceeded in a series of steps. Different multilevel models were assessed in order to first examine predictors in isolation, followed by their interaction with other predictors. As such, three primary nested models were examined. Gender effects were subsequently investigated for each primary model by adding gender as a moderator; this resulted in the combined examination of six nested models. Each model included actor couple satisfaction as the outcome variable.

All study models were initially examined by controlling for relationship length, number of children, and conventionality due to their demonstrated potential confounding effect(s) on the current study's primary variables (i.e., attachment, intimacy, couple satisfaction) and/or their interrelations (Creasey \& Hesson-McInnus, 2001; Hazan \& Shaver, 1984; Schaefer \& Olson, 1981; Wendorf, Lucas, Imamoglu, Weisfeld, \& Weisfeld, 2011). Given that the implementation of analyses including or excluding such potential confounds produced similar results, only models excluding these variables are presented in order to allow an improved and simplified interpretation of findings.

Additionally, provided that a small subset of individuals have been shown to concurrently display high levels of attachment anxiety and avoidance (and the corresponding use of both hyperactivation and deactivation strategies; Bartholomew \& Horowitz, 1991), we examined the potential interaction of attachment anxiety and avoidance in predicting the relation between intimacy and couple satisfaction in order to ensure a comprehensive assessment of the moderating role of romantic attachment. Specifically, LMM models were implemented by including all predictors (emotional and sexual intimacy, gender, attachment anxiety and avoidance) and the interactions of attachment (anxiety $\mathrm{x}$ avoidance $\mathrm{x}$ intimacy; anxiety $\mathrm{x}$ avoidance $\mathrm{x}$ intimacy $\mathrm{x}$ gender). Two separate models were tested, one including and one excluding gender as a predictor (as the inclusion of gender was shown to nullify some significant direct and interaction effects within our primary models as will be highlighted and presented subsequently). Given that no significant interaction effect of attachment anxiety and avoidance was found, that our primary objective was to explicitly differentiate between the dimensions of attachment anxiety and avoidance in isolation, and finally, that such dimensions are intended to be assessed and examined as distinct and orthogonal constructs (Brennan et al., 1998), the aforesaid attachment interactions will not be presented in succeeding analyses or discussed further. 


\subsubsection{Model 1: Emotional and Sexual Intimacy}

First, with the aim of examining whether actor and partner intimacy (emotional and sexual) were positively related to actor couple satisfaction (hypothesis 1), two models were tested. Model 1a included actor and partner intimacy (emotional and sexual intimacy; predictor variables). Analyses revealed that actor and partner emotional intimacy were significantly and positively related to actor couple satisfaction $\left(p<.001, \eta^{2}=.407 ; p<.05, \eta^{2}=.026\right.$, respectively). Conversely, actor and partner sexual intimacy were not found to be significantly related to actor couple satisfaction when examined concurrently with emotional intimacy (Note 1; see Table 2). Next, in order to examine the moderating role of gender on the above relations, all variables from model 1a were entered into model $1 \mathrm{~b}$ along with gender and their interactions. Analyses revealed that partner emotional intimacy was no longer significantly related to actor couple satisfaction upon entering gender into the model. However, gender was not found to moderate any relations.

Table 2. Emotional and sexual intimacy (actor and partner effects) on couple satisfaction (model 1a)

\begin{tabular}{lllllll}
\hline Fixed Effects & $\begin{array}{l}\text { Estimate } \\
\text { Coefficient }\end{array}$ & St. Error & t-value & $\begin{array}{l}\text { Lower } \\
95 \% \text { CI }\end{array}$ & $\begin{array}{l}\text { Upper } \\
95 \% \text { CI }\end{array}$ & p-value \\
\hline Intercept & .618 & .015 & 42.573 & .589 & .647 & .000 \\
Actor effects & & & & & & \\
$\quad$ EI & -.445 & .044 & -10.131 & -.532 & -.359 & $<.001$ \\
$\quad$ SI & -.017 & .045 & -0.389 & -.106 & .071 & .698 \\
Partner effects & & & & & & \\
$\quad$ EI & -.104 & .044 & -2.366 & -.191 & -.017 & $<.05$ \\
$\quad$ SI & -.036 & .045 & -0.794 & -.124 & .053 & .428
\end{tabular}

Note. Linear mixed model of emotional and sexual intimacy (actor and partner) in relation with couple satisfaction (actor). EI = emotional intimacy, SI = sexual intimacy; emotional and sexual intimacy are reflected values.

\subsubsection{Model 2: Intimacy x Romantic Attachment Anxiety}

Second, to examine whether actor attachment anxiety moderated the positive and non-significant relation between emotional and sexual intimacy and actor couple satisfaction, respectively (hypothesis 2), two models were tested. Model 2a included actor and partner emotional and sexual intimacy (predictor variables), actor attachment anxiety (moderator 1), and their interactions. Attachment anxiety was not found to moderate any relations (see Table 3). Next, in order to examine the moderating role of gender on the above relations, all direct and indirect relations investigated within model $2 \mathrm{a}$ were entered into model $2 \mathrm{~b}$ along with gender (moderator 2 ) and their interactions. Analyses revealed that the relation between partner emotional intimacy and actor couple satisfaction was no longer statistically significant upon entering gender into the model. Gender was not found to moderate any direct or indirect relations.

Table 3. Emotional and sexual intimacy (actor and partner effects) $\mathrm{x}$ actor attachment anxiety on couple satisfaction (model 2a)

\begin{tabular}{llllccc}
\hline Fixed Effects & $\begin{array}{l}\text { Coefficient } \\
\text { Estimate }\end{array}$ & $\begin{array}{l}\text { St. } \\
\text { Error }\end{array}$ & t-value & $\begin{array}{l}\text { Lower } \\
95 \% \text { CI }\end{array}$ & $\begin{array}{l}\text { Upper } \\
\text { CI }\end{array}$ & p-value \\
\hline Intercept & .618 & .015 & 40.582 & .588 & .649 & $<.001$ \\
Main effects & & & & & & \\
$\quad$ Actor Anxiety & -.129 & .081 & -1.582 & -.288 & .032 & .115 \\
$\quad$ Actor EI & -.421 & .046 & -9.106 & -.512 & -.330 & $<.001$ \\
\hline
\end{tabular}




\begin{tabular}{lllllll}
\hline Partner EI & -.111 & .044 & -2.523 & -.198 & -.024 & $<.05$ \\
$\quad$ Actor SI & -.015 & .045 & -.326 & -.103 & .074 & .745 \\
$\quad$ Partner SI & -.040 & .045 & -.885 & -.128 & .049 & .377 \\
Interaction effects & & & & & & \\
$\quad$ Actor Anxiety x EI & -.152 & .271 & -.560 & -.686 & .383 & .576 \\
Partner Anxiety x EI & -.381 & .253 & -1.506 & -.881 & .117 & .134 \\
Actor Anxiety x SI & .235 & .294 & .797 & -.345 & .814 & .426 \\
Partner Anxiety x SI & .354 & .260 & 1.363 & -.158 & .865 & .174 \\
\hline
\end{tabular}

Linear mixed model of the moderating role of attachment anxiety (actor) on the relation between emotional and sexual intimacy (actor and partner) and couple satisfaction (actor). Note. EI = emotional intimacy, SI = sexual intimacy; emotional and sexual intimacy are reflected values.

\subsubsection{Model 3: Intimacy x Romantic Attachment Avoidance}

Third, to examine whether actor attachment avoidance moderated the positive and non-significant relation between emotional and sexual intimacy and actor couple satisfaction, respectively (hypothesis 3), two models were tested. Model 3a included actor and partner emotional and sexual intimacy (predictor variables), actor attachment avoidance (moderator 1), and their interactions. Analyses revealed that actor attachment avoidance moderated the relation between actor emotional intimacy and actor couple satisfaction, such that individuals reporting higher levels of attachment avoidance demonstrated a weaker positive relation between their emotional intimacy and couple satisfaction when contrasted with individuals reporting lower attachment avoidance $(p<.01$, $\eta^{2}=.024$, see Table 4 for all LMM findings pertinent to this model; see Figure $1 \&$ Table 5 for plots and simple slope effects pertinent to the aforementioned interaction, respectively). No additional moderation effects of attachment avoidance were demonstrated. Next, in order to examine the moderating role of gender on the above relations, all direct and indirect links investigated within model $3 \mathrm{a}$ were entered into model $3 \mathrm{~b}$ along with gender (moderator 2) and their interactions. Analyses revealed that the relation between partner emotional intimacy and actor couple satisfaction was no longer statistically significant, nor was the interaction between actor emotional intimacy and actor attachment avoidance upon entering gender into the model. However, once more, gender was not found to moderate any relations.

Table 4. Emotional and sexual intimacy (actor and partner effects) $\mathrm{x}$ actor attachment avoidance on couple satisfaction (model 3a)

\begin{tabular}{lcccccc}
\hline Fixed Effects & $\begin{array}{l}\text { Coefficient } \\
\text { Estimate }\end{array}$ & St. Error & t-value & $\begin{array}{l}\text { Lower } \\
95 \% \text { CI }\end{array}$ & $\begin{array}{l}\text { Upper } \\
95 \% \text { CI }\end{array}$ & p-value \\
\hline Intercept & .600 & .016 & 37.539 & .570 & .627 & .000 \\
Main effects & & & & & & \\
$\quad$ Actor Avoidance & -.280 & .087 & -3.230 & -.450 & -.109 & $<.01$ \\
$\quad$ Actor EI & -.406 & .048 & -8.484 & -.501 & -.312 & $<.001$ \\
$\quad$ Partner EI & -.092 & .043 & -2.152 & -.177 & -.008 & $<.05$ \\
$\quad$ Actor SI & .029 & .046 & .616 & -.063 & .120 & .539 \\
$\quad$ Partner SI & -.036 & .044 & -.834 & -.122 & .049 & .405 \\
Interaction effects & & & & & & \\
$\quad$ Actor EI x Avoidance & .647 & .241 & 2.682 & .171 & 1.12 & $<.01$ \\
$\quad$ Partner EI x Avoidance & .121 & .220 & .549 & -.314 & .560 & .486 \\
$\quad$ Actor SI x Avoidance & -.260 & .267 & -.970 & -.781 & .266 & .333 \\
$\quad$ Partner SI x Avoidance & .026 & .244 & .105 & -.456 & .507 & .916 \\
\hline
\end{tabular}

Linear mixed model of the moderating role of attachment avoidance (actor) on the relation between emotional and sexual intimacy (actor and partner) and couple satisfaction (actor). EI = emotional intimacy, SI = sexual intimacy; emotional and sexual intimacy are reflected values. 


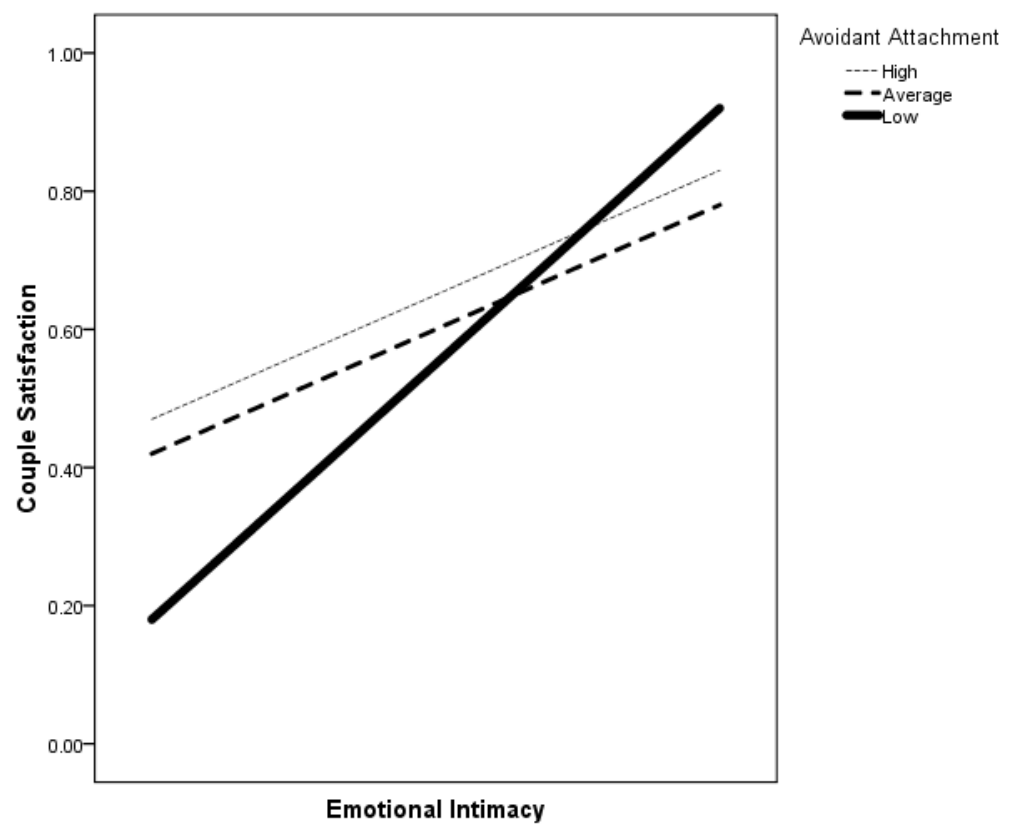

Figure 1. Graph of actor couple satisfaction as a function of actor emotional intimacy moderated by actor romantic attachment (Model 3a - logged values)

Table 5. Simple slope effects of actor couple satisfaction as a function of actor emotional intimacy moderated by actor attachment avoidance

\begin{tabular}{|c|c|c|c|c|}
\hline \multirow[b]{3}{*}{ Fixed Effects } & \multicolumn{4}{|c|}{ Moderator } \\
\hline & \multicolumn{2}{|c|}{ Low Avoidance } & \multicolumn{2}{|c|}{ High Avoidance } \\
\hline & B & $\mathrm{T}$ & B & $\mathrm{T}$ \\
\hline Intercept & .649 & 29.036 & .548 & 24.657 \\
\hline EI & -.523 & $-7.338 * * *$ & -.290 & $-5.065 * * *$ \\
\hline Avoidance & -.280 & $-3.230^{* *}$ & -.280 & $-3.230 * *$ \\
\hline EI x Avoidance & .647 & $2.682^{* *}$ & .647 & $2.682^{* *}$ \\
\hline
\end{tabular}

Note. Simple slope effects of the moderating role of attachment avoidance (actor) on the relation between emotional intimacy (actor) and couple satisfaction (actor). ${ }^{*} p<0.05,{ }^{* *} p<0.01,{ }^{* * *} p<0.001$, EI $=$ emotional intimacy, Avoidance $=$ attachment avoidance; emotional and sexual intimacy are reflected values.

\section{Discussion}

A plethora of studies exist demonstrating the important link between intimacy and couple satisfaction. Numerous studies have similarly revealed how attachment processes may influence intimacy motives and desires (Feeney \& Noller, 1991). This study was unique in expanding existing knowledge devoted to the understanding of intimacy by investigating how intimacy and attachment may interact on their relation with couple satisfaction. Accordingly, our primary objective was to examine the moderating role of actor romantic attachment on the association between intimacy and couple satisfaction. Novel explorations similarly included the multidimensional and dyadic examination and contrasting of actor versus partner effects of two facets of intimacy (emotional and sexual), as well as the investigation of the moderating role of gender amongst all links. Prior to elaborating on study results, a clarification of gender findings is first required.

\subsection{Intimacy and Gender}

Although entering gender into our models resulted in the loss of a significant relation between partner emotional intimacy and actor couple satisfaction, as well as the loss of an interaction effect (actor emotional intimacy $\mathrm{x}$ actor 
avoidant attachment), gender was not found to moderate any direct or indirect relations examined within the current study. Thus, our findings are aligned with previous research demonstrating no statistically significant difference between men and women as it pertains to the association between [emotional] intimacy and couple satisfaction (Sanderson \& Cantor, 2001). Given the absence of gender effects, only elaborations of models excluding gender will follow as this is believed to be more representative of the role of actor and partner intimacy and their link with couple satisfaction within the context of our findings.

\subsection{Actor versus Partner Emotional and Sexual Intimacy}

Results revealed that both emotional and sexual intimacy (actor and partner effects) were linked with higher levels of actor couple satisfaction when each respective facet of intimacy was examined in isolation. However, actor and partner sexual intimacy were no longer significantly related with actor couple satisfaction when examined concurrently with emotional intimacy. In this way, sexual intimacy did not appear to independently contribute to couple satisfaction when emotional intimacy levels were simultaneously considered. Thus, our study findings suggest that current experiences of intimacy created through emotional closeness, self-disclosure, and mutual feelings of connectedness may be a more important contributor to satisfactory couple relationships than sexual intimacy. Future research may seek to examine whether the attainment of higher levels of one facet of intimacy is influenced by the levels of intimacy acquired within the other facet. For instance, given the subsuming role of emotional intimacy over sexual intimacy for one's couple satisfaction, it is plausible that higher levels of emotional intimacy may occur irrespective of concurrent levels of sexual intimacy, whereas the reverse may be less likely to hold true within the context of long-term relationships.

Moreover, the current study demonstrated that although both actor and partner emotional intimacy were independently related to actor couple satisfaction, one's emotional intimacy accounted for a substantially higher proportion of one's couple satisfaction when contrasted with one's partner's emotional intimacy $(40.71 \%$ versus $2.60 \%$, respectively). The greater contribution of one's emotional intimacy suggests that the pursuit of higher levels of intimacy may require a particular focus on increasing an individual's subjective experience of intimacy (notwithstanding the acknowledged important dyadic nature of this relational experience). Research on close relationships reveals that individuals often project their intimacy goals unto their partner, often irrespectively of their partner's views and goals (Sanderson \& Evans, 2001). The use of one's level of intimacy as an overall gauge of both one's own and one's partner's intimacy may perhaps partially explain the stronger relation between one's emotional intimacy (relative to one's partner's emotional intimacy) and one's couple satisfaction.

\subsection{Moderating Role of Attachment}

Additionally, our study endeavoured to further extend current knowledge regarding the association between intimacy (emotional and sexual) and couple satisfaction by exploring an original moderation model of romantic attachment. Although noted that the absence of a significant relation between actor and partner sexual intimacy and actor couple satisfaction nullified our initial hypotheses regarding one's romantic attachment increasing or decreasing the strength of these relations, moderation effects were nevertheless feasible given that a significant relation between a predictor (e.g., sexual intimacy) and outcome variable (e.g., couple satisfaction) is not a required stipulation for demonstrating a moderation effect (Baron \& Kenny, 1986). As such, moderation effects were examined for both emotional and sexual intimacy and are subsequently elaborated upon for anxious attachment, followed by avoidant attachment.

Contrary to expected findings, results demonstrated that the relation between both emotional and sexual intimacy (actor and partner effects) and actor couple satisfaction was not influenced (i.e., moderated) by an individual's level of attachment anxiety. Although research has demonstrated that individuals with higher attachment anxiety generally incessantly seek out and desire higher levels of intimacy in their romantic relationship (Feeney \& Noller, 1991), higher reports of one's own or one's partner's intimacy did not render exacerbated increases in one's couple satisfaction. Prior studies have shown that anxiously attached individuals' continual attempts to attain higher intimacy (Mikulincer \& Shaver, 2007) can paradoxically undermine the level of intimacy they have acquired at each stage of their relationship (Feeney \& Noller, 1991). Perhaps then, transitory levels of intimacy, or the inability of higher levels of intimacy to fully satisfy anxiously attached individuals' unfulfilled need to feel secure or loved, limits a stronger relation between their intimacy (emotional and sexual) and couple satisfaction when present. Were the former inference accurate, a focus on reducing relationship features that undermine anxiously attached individuals' current experience of intimacy (e.g., intrusive attempts for greater intimacy; Lavy 2006) would appear to be particularly important for their attainment of higher levels of couple satisfaction.

With respect to partner effects of intimacy, research demonstrates that individuals exhibiting higher attachment anxiety are less accurate in perceiving their partner's feelings of love (Tucker \& Anders, 1999). Given that 
intimacy can be regarded as an expression and sentiment of love, inaccurate estimations of one's partner's intimacy may perhaps partially explain the lack of a stronger relation between one's partner's intimacy and one's couple satisfaction amongst individuals with higher attachment anxiety. If substantiated, this could imply that increasing one's awareness of their partner's emotional and sexual expressions indicative of love may also be beneficial for anxiously attached individuals' couple satisfaction. However, given the absence of moderation effects of attachment anxiety within the current study, it may simply be that once attained, higher levels of one's or one's partner's emotional and sexual intimacy are related to one's couple satisfaction in similar ways amongst individuals with higher or lower attachment anxiety. Accordingly, future research may seek to ascertain whether anxiously attached individuals' stronger desires for intimacy (Mikulincer \& Erev, 1991) results from their continual difficulty in aptly attaining and/or maintaining intimacy rather than stemming from an incessant and unlimited need for higher intimacy.

As it pertains to avoidant attachment, previous research has demonstrated that avoidantly attached individuals not only report having acquired, but moreover, desiring lower levels of intimacy in their romantic relationship (Collins \& Feeney, 2003). Our study expanded such findings by confirming our hypothesis stipulating that individuals with higher attachment avoidance would exhibit less increases in their couple satisfaction when experiencing higher levels of emotional intimacy. First, the substantiation of this inference suggests that despite higher levels of emotional intimacy generally increasing one's couple satisfaction, this may fail to occur to the same degree amongst those exhibiting higher attachment avoidance. Prior studies have shown that avoidant defences, such as the inhibition of emotions, can serve as a protective function against interpersonal closeness (Cassidy, 1994). Accordingly, when particular emotions are experienced by avoidantly attached individuals (e.g., higher emotional intimacy) that hinder regulatory efforts to minimize closeness and interdependence, lower couple satisfaction may be reported when compared to those without such regulatory goals. Hence, there appears to be particular dynamics at play, dynamics which may extend beyond avoidant defences (e.g., negative relational expectations), that hinder higher levels of intimacy to incrementally increase one's couple satisfaction to the same extent amongst individuals exhibiting higher attachment avoidance when contrasted with those reporting lower attachment avoidance.

However, while thus far emphasizing the impact of higher levels of intimacy, our findings similarly illustrated that when experiencing low levels of emotional intimacy, individuals exhibiting higher attachment avoidance reported higher levels of couple satisfaction when compared to individuals with lower avoidance. This may imply that the negative consequences typically arising from lower romantic intimacy are less intensely experienced by those with higher attachment avoidance. Thus, rather than limited desires for intimacy being invariably detrimental to one's romantic relationship, avoidant defences may serve adaptive functions such as defending against dissatisfaction when having a more distant partner and/or when experiencing lower levels of closeness in one's romantic relationship.

Contrary to our proposed hypothesis, a moderating effect was not found for partner emotional intimacy, such that individuals with higher attachment avoidance did not demonstrate lessened increases in their couple satisfaction when having a partner who reported higher levels of emotional intimacy. This suggests that one's emotional intimacy (relative to one's partner's intimacy) may be more likely to be experienced by individuals with higher attachment avoidance as a detriment to their preferred limits to interpersonal closeness. Such findings may conceivably be explained by avoidantly attached individuals' tendency to view their partner as requiring reduced levels of closeness and intimacy in order to protect and maintain one's own desired level of intimacy (Mikulincer \& Erev, 1991). As such, it may be that one's perception of their partner's intimacy, or alternatively, discrepancies in intimacy desires between partners, that contributes more to one's couple satisfaction than one's partner's reported intimacy.

Lastly, contrary to our expectation, a moderation effect of attachment avoidance was not demonstrated for the relation between sexual intimacy (actor or partner effects) and one's couple satisfaction. The absence of such findings may potentially be explained by avoidant individuals' outlook on sexual intimacy, specifically, their tendency to separate love and sex (Brennan \& Shaver, 1995). More explicitly, if avoidantly attached individuals' focus is primarily placed upon the physical needs gratified through sexual intimacy, as oppose to viewing this as a means of creating closeness, this may explain the absence of lessened increases in their couple satisfaction stemming from higher reports of one's or one's partner's sexual intimacy. This stipulation is consistent with past research which has demonstrated that avoidant individuals typically fail to express love and affection during sex (Birnbaum et al., 2006), are less likely to consider sex as a means by which to increase intimacy, and are correspondingly more likely to assess sexual satisfaction based on the physical components of sex (Davis et al., 2006). 
Alternatively, it is plausible that the absence of moderation effects of romantic attachment (anxiety or avoidance) on the relation between sexual intimacy and couple satisfaction is explained by the limited statistical power that can arise within the context of moderation analyses. More specifically, given a non-significant relation between sexual intimacy and couple satisfaction when examined alongside emotional intimacy, the modification of this relation (i.e., the attainment of a significant relation) would necessitate a particularly strong moderation effect of attachment; with research revealing that even a weak association between a predictor and outcome variable significantly lowers the power to find a moderation effect (Aguinis, 1995). Therefore, despite romantic attachment strategies utilized by individuals with anxious and avoidant attachment playing an important role in relationship functioning (Mikulincer \& Shaver, 2003), the magnitude of this influence may not exceed that required to alter the non-significant association demonstrated between sexual intimacy and couple satisfaction within our primary models. Prospective research implementing study procedures that are shown to improve the power to find moderation effects, for instance, the implementation of experimental manipulation studies (Aguinis, 1995; Aguinis et al., 2001), may ensure that moderation effects of attachment are not erroneously dismissed for sexual intimacy. However, given that emotional intimacy was shown to subsume sexual intimacy as it pertains to the association with couple satisfaction, it may simply be that emotional components are a more important feature of intimacy, and consequently, moderation effects of romantic attachment may only be pertinent to this facet.

\section{4 Limitations, Strengths, and Future Directions}

Despite the methodological strengths and novel explorations comprising the current study, its limitations must also be considered. First, the use of correlational data limits causal inferences that can be drawn from our findings. Although intimacy was postulated to impact couple satisfaction, it is similarly possible that couple satisfaction leads to greater intimacy or that each reciprocally influence one another. As such, prospective longitudinal studies are needed to determine causality. Second, despite a strength of the study being the use of a reasonably diverse array of dyads (e.g., common-law and married couples, varied relationship lengths, assorted ages, etc.) in a romantic relationship of at least 12 months duration, couples nevertheless tended to majorly consist of well-educated, Caucasian individuals in a predominantly highly-functioning heterosexual relationship. Thus, it cannot be assumed that the study's results are generalisable to all dating or married couples. Replication of our models amongst varied samples is required to ascertain the external validity of all findings, particularly amongst distressed couples who may exhibit lower levels of intimacy and couple satisfaction and/or higher levels of attachment insecurity. In short, results of the current study must be interpreted within the context of the particular sample used.

Third and lastly, there remain several research questions that were not addressed within the present study that could prospectively be addressed in future research. In order to circumvent multiple objectives and analyses (and the corresponding risk of type I or II errors) at the expense of a thorough understanding and explication of our models, the current study solely aimed to examine certain facets of intimacy and attachment and their relation with couple satisfaction. For instance, only the moderating role of actor romantic attachment, in contrast to partner attachment, was examined as the former was believed to play a more central and informative role within the context of our objectives. Although one's partner's attachment may influence one's experience of intimacy, in turn impacting one's couple satisfaction (implying mediation; aims which were outside the scope of the present study), the moderating role of partner attachment was deemed to be less applicable. Nonetheless, prospective studies may seek to examine (or rule out) whether intimacy and its relation with couple satisfaction differs based on the attachment of both partners of a dyad (i.e., actor and partner attachment) or particular dyad types (e.g., secure/secure, avoidant/anxious couples, etc.).

Moreover, given greater empirical evidence for the established relation between emotional and sexual intimacy and couple satisfaction when contrasted with other facets of intimacy, the former facets were deemed to be most appropriate for instigating investigations ascertaining the moderating role of attachment. Nonetheless, prospective studies may seek to examine the broader applicability of our models to other facets of intimacy (e.g., recreational intimacy, intellectual intimacy, etc.) or differing frames of reference for measuring intimacy (e.g., desired, perceived, versus experienced intimacy). Lastly, as previously alluded to, future research may seek to implement more advanced procedural methods (e.g., observational and/or experimental manipulation studies) in order to verify the robustness of all significant and non-significant moderation effects explored within the current study.

\subsection{Conclusions}

Consistent with previous research, our results further confirmed the significant role of intimacy in attaining satisfactory couple relationships (Greeff \& Malherbe, 2001; Schaefer \& Olson, 1981). The present study's novel 
incorporation of an attachment perspective further extended this knowledge by revealing differences in the strength of the relation between emotional intimacy and couple satisfaction as a function of one's romantic attachment. Accordingly, our findings provided support for attachment theory as a valuable framework by which to comprehend underlying idiosyncratic intimacy-based motives and experiences (Collins \& Feeney, 2003; Feeney \& Noller, 1991) and their corresponding differential relation with couple satisfaction. In practical terms, this understanding may prove to be a useful [preventive and/or therapeutic] tool in maintaining or increasing satisfaction in romantic relationships. Furthermore, given research revealing that couples tend to report greater satisfaction when they are aware of their partner's goals, irrespective of those goals (Sanderson and Cantor, 2001), understanding for whom intimacy may be differentially related to one's couple satisfaction may similarly aid in this endeavour. More broadly, our findings illuminated how levels of emotional intimacy required for satisfactory relationships may vary from individual to individual or couple to couple, providing empirical support for Schaefer and Olson's (1981) proposition that there exists no standard level of intimacy. As such, consistent with this notion, it is our contention that satisfactory relationships likely require intimacy needs to be distinctively and mutually determined by the needs of both partners of a dyad rather than an invariable striving towards a universal standard. Attachment theory provides an innovative angle by which to understand differences in emotional intimacy and its relation with couple satisfaction.

\section{Acknowledgements}

This study was funded by two Social Sciences and Humanities Research Council grants (0100-410-2004 and 767-2009-1783). We would like to extend our gratitude to Dr. Dwayne Schindler for his guidance during our implementation of statistical analyses, as well as all the graduate students at the Couple Research Lab for their assistance with data collection.

\section{References}

Aguinis, H. (1995). Statistical power problems with moderated multiple regression in management research. Journal of Management Research, 21, 1141-1158. http://dx.doi.org/10.1177/014920639502100607

Aguinis, H., Boik, R. J., \& Pierce, C. A. (2001). A generalized solution for approximating the power to detect effects of categorical moderator variables using multiple regression. Organizational Research Methods, 4, 291-323. http://dx.doi.org/10.1177/109442810144001

Aiken, L. S., \& West, S. G. (1991). Multiple regression: Testing and interpreting interactions. Newbury Park, CA: Sage.

Baron, R. M., \& Kenny, D. A. (1986). The moderator-mediator variable distinction in social psychological research: Conceptual, Strategic, and Statistical Considerations. Journal of Personality and Social Psychology, 51, 1173-1982. http://dx.doi.org/10.1037/0022-3514.51.6.1173

Bartholomew, K., \& Horowitz, L. M. (1991). Attachment styles among young adults: A test of a four category model. Journal of Personality and Social Psychology, 61, 226-244. http://dx.doi.org/10.1037/0022-3514.61.2.226

Birnbaum, G. E., Reis, H. T., Mikulincer, M., Gillath, O., \& Orpaz, A. (2006). When sex is more than just sex: Attachment orientations, sexual experience, and relationship quality. Journal of Personality and Social Psychology, 91, 929-943. http://dx.doi.org/10.1037./0022-3514.91.5.929

Bowlby, J. (1969/82). Attachment and Loss: Vol 1. Attachment (2nd ed.). New York: Basic Books.

Brennan, K. A., Clark, C. L., \& Shaver, P. R. (1998). Self-report measurement of adult attachment: An integrative overview. In J. A. Simpson \& W. S. Rholes (Eds.), Attachment theory and close relationships (pp. 46-76). New York: Guilford Press.

Brennan K. A., \& Shaver, P. R. (1995). Dimensions of adult attachment, affect regulation, and romantic relationship functioning. Personality and Social Psychology Bulletin, 21, 267-283. http://dx.doi.org/10.1177/0146167295213008

Brennan, K. A., Wu, S., \& Loev, J. (1998). Adult romantic attachment and individual differences in attitudes toward physical contact in the context of adult romantic relationships. In J. A. Simpson \& W. S. Rholes (Eds.), Attachment theory and close relationships (pp. 394-428). New York: Guilford Press.

Campbell, L., \& Kashy, C. (2002). Estimating actor, partner, and interaction effects for dyadic data using PROC mixed and HLM: A user friendly guide. Personal Relationships, 9, 327-342. http://dx.doi.org/10.1111/1475-6811.00023 
Cohen, J., Cohen, P., West, S. G., \& Aiken, L. S. (2003). Applied Multiple regression/correlation analysis for behavioural sciences (3rd ed.). Mahwah, New Jersey: Erlbaum.

Cook, W. L., \& Kenny, D. A. (2005). The actor-partner interdependence model: A model of bidirectional effects in developmental studies. International Journal of Behavioral Development, 29, 101-109. http://dx.doi.org/10.1080/01650250444000405

Cassidy, J., \& Berlin, L. J. (1994). The insecure/ambivalent pattern of attachment: Theory and research. Child Development, 65, 971-981. http://dx.doi.org/10.2307/1131298

Cassidy, J., \& Kobak, R. R. (1988). Avoidance and its relationship with other defensive processes. In J. Belsky \& T. Nezworski (Eds.), Clinical implications of attachment (pp. 300-323). New Jersey: Erlbaum.

Collins, N. L., \& Feeney, B. C. (2003). Social support and caregiving in daily interactions: Feeling supported and feeling secure. Unpublished Manuscript, University of California, Santa Barbara.

Collins, N. L., \& Read, S. (1990). Adult attachment, working models, and relationship quality in dating couples. Journal of Personality and Social Psychology, 58, 644-663. http://dx.doi.org/10.1037/0022-3514.58.4.644

Cohen, J., Cohen, P., West, S. G., \& Aiken, L. S. (2003). Applied Multiple Regression/Correlational Analyses for Behavioral Sciences (3rd ed.). New Jersey: Laurence Erlbaum Associate Publishers.

Creasey, G., \& Hesson-McInnus, M. (2001). Affective responses, cognitive appraisals, and conflict tactics in late adolescent romantic relationships associations with attachment orientations. Journal of Counseling Psychology, 48, 85-96. http://dx.doi.org/10.1037/0022-0167.48.1.85

Davis. D., Shaver, P. R., Widaman, K. F., Vernon, M. L., Follette, W. C., \& Beitz, K. (2006). "I can't get no satisfaction", Insecure attachment, inhibited sexual communication, and sexual dissatisfaction. Personal Relationships, 13, 465-483. http://dx.doi.org/10.1111/j.1475-6811.2006.00130.x

Erikson, E. (1950). Childhood and society. New York: Norton.

Faul, F., Erdfelder, E., Lang, A. G., \& Buchner, A. (2007). G*Power 3: A flexible statistical power analysis program for the social, behavioral, and biomedical sciences. Behavior Research Methods, 39, 175-191. http://dx.doi.org/10.3758/BF03193146

Feeney, J. A. (1999). Issues of closeness and distance in dating relationships: Effects of sex and attachment style. Journal of Social and Personal Relationships, 16, 571-590. http://dx.doi.org/10.1177/0265407599165002

Feeney, J. A., \& Collins, N. L. (2003). Motivations for caregiving in adult intimate relationships. An attachment theoretical perspective. Journal of Personality and Social Psychology, 80, 972-994. http://dx.doi.org/10.1177/0146167203252807

Feeney, J. A., \& Noller (1991). Attachment style and verbal descriptions of romantic partners. Journal of Social and Personal Relationships, 8, 187-215. http://dx.doi.org/10.1177/0265407591082003

Fraley. S. L., \& Shaver, P. R. (2000). Adult Romantic Attachment: Theoretical Developments, Emerging Controversies, and Unanswered Questions. Review of General Psychology, 4, 132-154. http://dx.doi.org/10.1037/1089-2680.4.2.132

Fraley, S. L., Waller, N. G., \& Brennan, K. A. (2000). An item response theory analysis of self-report measure of adult attachment. Journal of Personality and Social Psychology, 78, 350-365. http://dx.doi.org/10.1037//0022-3514.78.2.350

Greeff, A. P., \& Malherbe, H. L. (2001). Intimacy and martial satisfaction in spouses, Journal of Sex and Marital Therapy, 27, 247-257. http://dx.doi.org/10.1080/009262301750257100

Guerrero, L. K. (1996). Attachment style differences in intimacy and involvement: A test of the four-category model. Communication Monographs, 63, 269-294. http://dx.doi.org/10.1080/03637759609376395

Hazan, C., \& Shaver, P. R. (1987). Romantic love conceptualized as an attachment process. Journal of Personality and Social Psychology, 52, 511-524. http://dx.doi.org/10.1037/0022-3514.52.3.511

Hazan, C., Zeifman, D., \& Middleton, K. (1994). Adult romantic attachment, affection and sex. Paper presented at the International Conference on Personal Relationships, Groningen, NL.

Hendrick, S. S. (1988). A generic measure of relationship satisfaction. Journal of Marriage and the Family, 50, 93-98. http://dx.doi.org/10.2307/352430

Hobfoll, S. E., \& Leiberman, J. R. (1989). Effects of mastery and intimacy on anxiety following pregnancy: For 
whom is support supportive and from whom? Anxiety Research, 1, 327-341. http://dx.doi.org/10.1080/08917778908248729

Hook, M. K., Gerstein, L. H., Detterich, L., \& Gridely, B. (2003). How close are we? Measuring intimacy and examining gender differences. Journal of Counselling and Development, 81, 462-472. http://dx.doi.org/10.1002/j.1556-6678.2003.tb00273.x

Horowitz, M. J. (1979). States of mind: Analysts of change in psychotherapy. New York: Plenum Publishing.

Kenny, D. A., \& Cook, W. (1999). Partner effects in relationship research: Conceptual issues, analytic difficulties, and illustrations. Personal Relationships, 6, 433-448. http://dx.doi.org/10.1111/j.1475-68111999.tb00202.x

Kenny, D. A., Kashy, D. A., \& Cook, W. L. (2006). Dyadic Data Analysis. New York: The Guilford Press.

Lavy, S. (2006). Expressions and consequences of intrusiveness in adult romantic relationships: An attachment theory perspective. Unpublished doctoral dissertation, Bar-Ilan University, Ramat Gan, Israel.

Marelich, W. D. (2008). Motivations for sexual intimacy: Development of a needs based Sexual Intimacy Scale. International Journal of Sexual Health, 20, 177-186. http://dx.doi.org/10.1080/19317610802240121

McCabe, M. P. (1999). The interrelationship between intimacy, relationship functioning, and sexuality among men and women in committed relationships. The Canadian Journal of Human Sexuality, 8, 31-40.

Mikulincer, M., \& Erev, I. (1991). Attachment style and the structure of romantic love. British Journal of Social Psychology, 30, 273-291. http://dx.doi.org/10.1111/j.2044-8309.1991.tb00946.x

Mikulincer, M., \& Shaver, P. R. (2003). The attachment behavioural system in adulthood: Activation, psychodynamics, and interpersonal processes. In M. P. Zanna (Ed.), Advances in experimental social psychology (Vol. 35, pp. 53-152). New York, NY: Academic Press.

Milkulincer, M., \& Shaver, P. R. (2007). Attachment in adulthood: Structure, dynamics and change. New York: The Guilford Press.

Miller, R. S., \& Lefcourt, H. M. (1982). The assessment of social intimacy. Journal of Personality Assessment, 46, 514-518. http://dx.doi.org/10.1207/s15327752jpa4605_12

Morris, L. W., Morris, R. G., \& Britton, P. G. (1988). The relationship between marital intimacy, perceived strain and depression in spouse caregivers of dementia sufferers. British Journal of Medical Psychology, 61, 231-236. http://dx.doi.org/10.1111/j.2044-8341.1988.tb02784.x

Oden, T. C. (1974). Game free: A guide to the meaning of intimacy. New York: Harper \& Row.

Ognibene, T. C., \& Collins, N. L. (1998). Adult attachment styles, perceived social support, and coping strategies. Journal of Social and Personal Relationships, 18, 199-221. http://dx.doi.org/10.1177/0265407598153002

Pielage, S. B., Luteijn, F., \& Arrindell, W. A. (2005). Adult attachment, intimacy, and psychological distress in a clinical and community sample. Clinical Psychology and Psychotherapy, 12, 455-464. http://dx.doi.org/10.1002/cpp.472

Pistole, M. C. (1994). Adult attachment styles: some thoughts on closeness-distance struggles. Family Process, 33, 147-159. http://dx.doi.org/10.1002/cpp.472

Prager, K. J., \& Roberts, L. J. (2004). Deep intimate connection: Self and intimacy in couple relationships. In D. J. Mashek \& A. Aron (Eds.), Handbook of closeness and intimacy (pp. 163-188). London: Lawrence Erlbaum Associates Publishers.

Reis, H. (1998). Gender differences in intimacy and related behaviors: Context and process. In K. Dindia \& D. J. Canary (Eds.), Sex differences and similarities in communication: Critical essays and empirical investigations of sex and gender in interaction (pp. 203-231). New Jersey: Lawrence Erlbaum Associates.

Reis, H. T., \& Patrick, B. C. (1996). Attachment and Intimacy: Component processes. In E. T. Higgins \& A. W. Kruglanski (Eds.), Social psychology: Handbook of personal relationships: Theory, research and interventions (pp. 523-563). New York: Guilford Press.

Reis, H. T., \& Shaver, P. (1988). Intimacy as an interpersonal process. In S.W. Duck (Ed.), Handbook of personal relationships: Theory, research, and intervention (pp. 367-389). Chichester, UK: Wiley.

Rogers, C. R. (1972). On becoming a person. Boston: Houghton Mifflin.

Sabourin, S., Valois, P., \& Lussier, Y. (2005). Development and validation of a brief version of the Dyadic Adjustment Scale with a nonparametric item analysis model. Psychological Assessment, 17, 15-27. 
http://dx.doi.org/ 10.1037/1040-3590.17.1.15

Sanderson, C. A., \& Cantor, N. (2001). The association of intimacy goals and marital satisfaction: A test of four mediational models hypotheses. Personality and Social Psychology Bulletin, 27, 1567-1577. http://dx.doi.org/10.1177/01461672012712001

Sanderson, C. A., \& Evans, S. M. (2001). Seeing one's partner through intimacy colored glasses: An examination of the processes underlying the intimacy goals-relationship satisfaction link. Personality and Social Psychology Bulletin, 27, 463-473. http://dx.doi.org/10.1177/0146167201274007

Schaefer, M. T., \& Olson, D. H. (1981). Assessing Intimacy: the PAIR Inventory. Journal of Marital and Family Therapy, 7, 47-60. http://dx.doi.org/10.1111/j.1752-0606.1981.tb01351.x

Sexton, R. E., \& Sexton, V. S. (1982). Intimacy: A historical perspective. In M. Fisher \& G. Stricker (Eds), Intimacy (pp. 1-20). New York: Plenum Press.

Spanier, G. B. (1976). Measuring dyadic adjustment: New scales for assessing the quality of marriage and similar dyads. Journal of Marriage and the Family, 38, 15-28. http://dx.doi.org/10.2307/350547

Sullivan, H. S. (1953). The interpersonal theory of psychiatry. New York: Norton.

Tabachnick, B. G., \& Fidell, L. S. (2007). Using multivariate statistics (5th ed.). New York: Pearson Education Inc.

Tolstedt, B. E., \& Stokes, J. P. (1983). Relation of verbal, affective, and physical intimacy to marital satisfaction. Journal of Counseling and Psychology, 4, 573-580. http://dx.doi.org/10.1037/0022-0167.30.4.573

Wendorf, C. A., Lucas, T., Imamoglu, E. O., Weisfeld, C. C., \& Weisfeld, G. E. (2011). Marital satisfaction across three cultures: Does the number of children have an impact after accounting for other marital $\begin{array}{lllll}\text { demographics? Journal of } & \text { Cross-Cultural }\end{array}$ http://dx.doi.org/10.1177/0022022110362637

Widaman, W. F. (2006). Missing data: What to do with or without them [Monograph]. Best Practices in $\begin{array}{lllll}\text { Quantitative } & \text { Methods }\end{array}$ http://dx.doi.org/10.1111/j.1540-5834.2006.00404.x

\section{Notes}

Note 1. When sexual intimacy was examined in isolation from emotional intimacy, both actor and partner effects of sexual intimacy were significantly and positively related to actor couple satisfaction. 